\title{
Assessment of Jordanian Patient's Colorectal Cancer Awareness and Preferences towards CRC Screening: Are Jordanians Ready to Embrace CRC Screening?
}

\author{
Suha Omran ${ }^{1 *}$,Husam Barakat ${ }^{2}$, Joshua Kanaabi Muliira $^{3}$, Ibrahim Bashaireh ${ }^{4}$, \\ Abdul-Moni'm Batiha ${ }^{5}$
}

\begin{abstract}
Background: Colorectal cancer (CRC is increasingly becoming a major cause of cancer morbidity and mortality in Jordan. However the population's level of awareness about CRC, CRC screening test preferences and willingness to embrace screening are not known. The aim of this study was to assess the level of CRC awareness and screening preferences among Jordanian patients. Materials and Methods: A survey assessing the CRC knowledge levels was distributed among patients attending outpatient gastroenterology clinics in public hospitals throughout Jordan. A total of 800 surveys were distributed and of these $713(89.1 \%)$ were returned. Results: Only $22 \%$ of the participants correctly judged CRC among the choices provided as the commonest cause of cancer related deaths. The majority of participants $(68.3 \%)$ underestimated their risk for CRC. Only $26.8 \%$ correctly judged their life time risk while $5 \%$ overestimated their risk. Two thirds of participants $(66 \%)$ were willing to pay 500 Jordanian Dinars (equivalent to 706 US\$) in order to get a prompt colonoscopy if recommended by their physician, while $25.5 \%$ reported that they would rather wait for 6 months in order to get a free colonoscopy. Conclusions: Although the participants tended to underestimate their risk for CRC, they were mostly aware of CRC as a major cause of mortality and were willing to embrace the concept of CRC screening and bear the related financial costs. These findings about CRC awareness and propensity for screening provide a good foundation as the Jordanian health system moves forward with initiatives to promote CRC screening and prevention.
\end{abstract}

Keywords: Colorectal cancer - cancer screening - colonoscopy - knowledge - Jordanian

Asian Pac J Cancer Prev, 16 (10), 4229-4235

\section{Introduction}

Colorectal cancer (CRC) is the second leading cause of death in most western and developed countries (American Cancer Society 2005; National Institute of Health, 2008; Tarawneh \& Nimri, 2008). In Jordan, a country located in the Middle East, CRC is steadily becoming a significant health problem which contributes the population's morbidity and mortality. CRC is the second most prevalent type of cancer among Jordanian (Tarawneh and Nimri, 2008). Among Jordanian men, CRC is the leading type of cancer (ranked first, $13.7 \%$ of all cancer types) and it is the second leading cause of cancer among females (10.6\%) (National Cancer Registry (NCR), 2010). The median age at diagnosis of colon cancer in Jordanian males and females is 60 years and 64 years, respectively (NCR, 2010). For rectal cancer the median age at diagnosis in Jordanian males and females is 59 years and 56 years, respectively (NCR, 2010).

According to the World Health Organization (WHO), in a Jordan a country of 7 million people, CRC is responsible for $16.1 \%$ and $14.4 \%$ of the cancer mortality in men and women, respectively (WHO, 2015). The burden of CRC is expected to continue rising because of the high prevalence of the associated risk factors among Jordanians. There are many risk factors for CRC and these include age older than 50 years, family history of CRC, high consumption of red meat and fat, with low intake of vegetables and fibers, obesity, and chronic inflammatory bowel disease (Umar and Greenwald, 2009; Huxley, Ansary-Moghaddam, Clifton et al, 2009; Musaiger, 2004). Recent statistics show that in Jordan the prevalence of risk factors such as tobacco smoking (26.2\%), physical inactivity $(12.1 \%)$ and obesity $(28.1 \%)$ are very high among adults (WHO, 2015).

However, the morbidity and mortality due to CRC deaths can be prevented or curtailed through use of screening tests to detect the disease at early stage (Hardcastle, 1996; Agency for Health Care Policy and Research, 2005). CRC screening is a very important

${ }^{1}$ Jordan University of Science and Technology, Faculty of Nursing/Adult Health Department, Irbid, ${ }^{2}$ Ibn AlHaytham Hospital Gastroenterology Department, Amman, ${ }^{3}$ College of Nursing Sultan Qaboos University Nursing Muscat, Oman, ${ }^{4,5}$ Adult Health Department/College of Nursing, Philadelphia University, Amman*For correspondence: suha31@just.edu.jo 
approach to prevention of this type of cancer because it reduces both incidence through removal of premalignant polyps and $\mathrm{CRC}$ deaths through early detection and therefore timely referral for treatment (Hannon et al., 2009). CRC screening is well suited for early detection of precancerous polyps which precede the development of malignancies (American Cancer Society, (ACS), 2006).

Research done over several decades has increased our understanding of the CRC screening modalities and frequency of performing the screening tests (Mandel et al., 1993; Lieberman, 1995; Winawer et al., 2003). Several CRC screening modalities are endorsed and have been used to develop practice guidelines which are widely used in developed countries (U.S. Preventive Services Task Force, 2002; Schoen et al., 2012). As result CRC screening in an average risk, asymptomatic adult person is now widely recommended starting at the age of 50 years (McFarland et al., 2008; WHO, 2011). The CRC screening guidelines commonly recommend CRC screening using- colonoscopy every 10 years; or fecal occult blood test or fecal immunological test every year; or flexible sigmoidoscopy every 5 years (U.S. Preventive Services Task Force, 2010; ACS, 2006).

Available evidence suggests that when CRC screening is properly and promptly provided it can reduce CRC mortality by $16 \%$ to $33 \%$ (Hardcastle et al., 1996; U.S. Preventive Services Task Force, 2002). This is mainly because CRC survival is closely related to the clinical and pathological stage of the disease at time of diagnosis. Apart from reducing the risk of death; CRC screening also reduces the cost of care. Despite the benefits of CRC screening and the plethora of scientific evidence about its effectiveness, the screening rates are still low in at risk populations (Swan et al., 2003; Seef et al., 2004; Meissner et al., 2006; Shapiro et al., 2008). It has been reported that cancer screening rates are affected by the levels of knowledge and awareness of the disease by the people, and other factors such as cost and lack of access to screening tests (Winawer etal., 2003; Dolan et al., 2004; Omran and Ismail, 2010). Increased knowledge about $\mathrm{CRC}$ and screening encourage people to use the service, whereas a lack of knowledge hinders people use of these services (Klabunde et al., 2006). Access to CRC screening services and cost of services also play a very crucial role in determining CRC screening utilization and subsequently affects cancer prevention in a country.

In Jordan the health authorities have instituted strategies such as developing operational cancer policies and action plans, having a cancer registry, and provision of CRC screening services in public primary health care settings to enhance cancer prevention (WHO, 2015). The CRC screening test that is mostly available in the public primary health care settings is fecal occult blood testing or fecal immunological test (WHO, 2015). The other CRC screening tests such as bowel cancer screening by examination, colonoscopy, and flexible sigmoidoscopy are not available in the public primary care setting, but in regional hospitals (2015). Considering the limited access to all the CRC screening tests in Jordanian public primary care settings and the high CRC mortality, it is important to establish population knowledge levels and readiness to embrace CRC screening. Therefore the purpose of this study was to assess the level of CRC awareness and screening preferences among Jordanian patients. The findings of this study can provide needed insights before scaling up national initiatives to enhance CRC screening and promote cancer prevention.

\section{Materials and Methods}

\section{Design and sample}

The study used a descriptive and cross-sectional design to collect data from a convenience sample of 713 participants. The researchers recruited the study participants from the largest Ministry of Health Hospitals in the three geographic regions of Jordan (Central, Northern, and Southern regions). In Jordan there are four major health care services providers and these include the Ministry of Health (MOH), the Royal Medical Services (Military), Private hospitals, and the university medical centers (the Jordan University in Amman and the King Abdullah Hospital in Irbid). The hospitals managed by the $\mathrm{MOH}$ are fully funded by the government; all citizens of Jordan can be treated in theses hospital without paying. The majority of Jordanian receives their health care from the ministry of health hospitals. The sample for this study was recruited from outpatient gastroenterology clinic in selected hospitals In order to be included in the study the participants had to be Jordanian by nationality, of age 50 years and above, and able to read and write in Arabic. Individuals with a known personal history or diagnosis of CRC were excluded from the study.

\section{Instrument}

The instrument used to collect data was comprised of a Demographic Data Sheet (DDS) and items to measure CRC knowledge and preferences. The DSS had item eliciting information about the participant's age, gender, marital status, education level, occupation, income, and health insurance status and participants health status. The items to measure the CRC awareness and preferences were developed by the researcher. The items focused on eliciting data from participants about ranking of CRC as a cause of death, personal risk of CRC, risk factors for $\mathrm{CRC}$, warning symptoms of $\mathrm{CRC}$, and preferences for the three CRC screening tests (Fecal Occult Blood (FOB), Colonoscopy, and Flexible Sigmoidoscopy). The question assessing rank of CRC and lifetime risk required selection of a single correct answer. Other questions relating to CRC risk factors and warning symptoms allowed participants selection from multiple options.

The participants also responded to items requiring them to state their willingness to undergo CRC screening, their willingness to pay money for colonoscopy if recommended by their doctors, and their preferred type of CRC screening test (Colonoscopy, FOBT, and Flexible Sigmoidoscopy). The study questionnaire was given to 10 experts (gastroenterology, nursing, and researcher or statistician) to review it for accuracy and face and content validity. The questionnaire was adjusted using comments from the experts, before it was pilot tested. The feedback about the questions from the experts was mostly about 
its length and the time required to complete and code the responses.

The study questionnaire was pretested among 30 people (meeting the same eligible sample criteria) for clarity, logical flow, and time required respond to all the items. The reliability of the study questionnaire was tested using Cronbach's alpha and found to be 0.76 .

\section{Data collection procedure}

Prior to initiation of data collection, approval from the Institutional Review Boards of The Jordan University of Science and Technology, and the hospitals used for the study was obtained. During data collection days, the survey was distributed to all patients attending outpatient gastroenterology clinics in Jordan who met the inclusion criteria. Data for this study was collected over a period of six consecutive months (June to December, 2014). The researchers identified potential participants from the outpatient clinic at the time of registration, and each participant was offered the option of completing the study questionnaire while waiting to see health care provider for their appointment. Only the participants who gave written consent to participate in the study were allowed to complete the survey. The study questionnaire required between 15-20 minutes to complete.

\section{Data analysis}

The data of continuous variables analyzed was using descriptive statistics such as percentage, means and standard deviations. The categorical variables were compared using chi squared test. A p value of 0.05 was considered statistically significant.

\section{Results}

\section{Description of the sample}

The survey was distributed to 800 participants and a total of $713(89.1 \%)$ returned the completed survey. The results summarized in Table 1 show that the majority of participants were male $(71.8 \%)$, married $(88.1 \%)$, reported an annual income of less than 4229 US dollars and had only the public health insurance given by the government (70.5\%). The mean age of the participant included in the sample was 57 years $(\mathrm{SD}=8.56)$.

\section{Participant's awareness of colorectal cancer}

The results presented in Table 2 show that only $22.3 \%$ of participants correctly judged that CRC is the commonest cause of cancer related deaths in Jordan among the options provided. The most commonly known risk factors for CRC were smoking (71.7\%), alcohol use (48.1\%) and family history of CRC (39.7). Very few participants were aware that overweight or obesity is a risk factor for CRC (14.4\%). The symptoms of CRC the participants were mostly aware of include rectal bleeding (42.2\%), flatulence $(48.8 \%)$ and having diseases of the digestive system (35.8\%). Only $26.8 \%$ correctly judged their life time risk of CRC cancer, while $5 \%$ of the participants overestimated their risk for CRC. Additional analysis showed that more males than females judged prostate cancer to be among the commonest cause of cancer deaths
Table 1. Characteristics of the Study Participants

\begin{tabular}{|c|c|c|}
\hline Characteristic & Category & $\begin{array}{r}\mathrm{N}=713 \\
\text { Frequency }(\%)\end{array}$ \\
\hline \multicolumn{3}{|l|}{ Age in years } \\
\hline & $\leq 50$ & $167(23.4 \%)$ \\
\hline \multicolumn{3}{|c|}{$(\mathrm{M}=57.01 ; \mathrm{SD}=8.56)$} \\
\hline & $>50$ & $537(75.3 \%)$ \\
\hline \multirow{2}{*}{ Gender } & Male & $512(71.8 \%)$ \\
\hline & Female & $201(28.2 \%)$ \\
\hline \multirow[t]{3}{*}{ Marital status } & Single & $12(1.7 \%)$ \\
\hline & Married & $628(88.1 \%)$ \\
\hline & Divorced or widowed & $73(10.2 \%)$ \\
\hline \multirow[t]{4}{*}{ Level education } & Less than secondary school & $433(60.7 \%)$ \\
\hline & Secondary school & $126(17.7 \%)$ \\
\hline & Diploma & $43(6 \%)$ \\
\hline & Bachelor and above & $111(15.6 \%)$ \\
\hline \multicolumn{3}{|c|}{ Employment status } \\
\hline & Employed & $298(41.8 \%)$ \\
\hline & Not employed & $189(26.5 \%)$ \\
\hline & Retired & $226(31.7 \%)$ \\
\hline \multicolumn{3}{|c|}{ Level of annual income in Jordanian Dinars } \\
\hline & $\leq 2999(\leq 4229$ US \$ $)$ & $473 \quad(66 \%)$ \\
\hline & $3000-4999(4230-7048$ US\$) & ) $108(15.1 \%)$ \\
\hline & $\geq 5000(7049$ US\$) & $132(18.5 \%)$ \\
\hline \multicolumn{3}{|c|}{ Health insurance status } \\
\hline & Public & $503(70.5 \%)$ \\
\hline & Private & $168(23.5 \%)$ \\
\hline & None & $42(5.9 \%)$ \\
\hline \multicolumn{3}{|c|}{ Self-rated health status } \\
\hline & Very good or excellent & $253(35.5 \%)$ \\
\hline & Good & $323(45.3 \%)$ \\
\hline & Poor or fair & $37(19.2 \%)$ \\
\hline \multicolumn{3}{|c|}{ Number of relatives with colorectal cancer } \\
\hline & None & $2(0.3 \%)$ \\
\hline & $\leq 2$ Relative & $42(5.9 \%)$ \\
\hline & $\geq 3$ Relative & $7(1 \%)$ \\
\hline \multicolumn{3}{|c|}{ Chronic health conditions (multiple responses) } \\
\hline & Hypertension & $247(38.4 \%)$ \\
\hline & Other heart diseases & $67(9.4 \%)$ \\
\hline & Diabetes mellitus & $172(24.1 \%)$ \\
\hline & Digestive system disease & $68(9.5 \%)$ \\
\hline & Nervous system disease & $3(0.4 \%)$ \\
\hline
\end{tabular}

( $22.4 \%$ versus $4.4 \%$, respectively; $\mathrm{p}=0.000)$. Fewer older males $(17.3 \%)$ judged CRC to be the commonest cause of death among the choices provided compared to younger males $(6.85 \%, \mathrm{p}=0.014)$, and younger females $(4 \%$, $\mathrm{p}=0.228$ ). And more females than males judged breast cancer to be the commonest cancer deaths $(31.6 \%$ versus $21.3 \%$, respectively; $\mathrm{p}=0.000$ ).

\section{Participant's colorectal cancer screening preferences}

The results presented in Table 3 show that almost 50\% of the participants were willing to undergo CRC screening with a larger proportion of older males (37\%) compared to younger males $9.5 \%$ more likely to be ready to undergo CRC than females (36.3\% older, $19.9 \%$ younger). Most of the participants (60.4\%) preferred colonoscopy for CRC screening. The majority of participants $(65.5 \%)$ were willing to pay 500 Jordanian Dinars (equivalent to 706 US\$) to get prompt colonoscopy if recommended by their physician while others reported that they will wait up to 6 months to get free service $(25.5 \%)$ or refuse colonoscopy (9\%). The participants' gender was significantly associated with willingness to undergo $\mathrm{CRC}$ screening $(\mathrm{p}=0.025)$ 
Table 2. Participants' Awareness of Colorectal Cancer

\begin{tabular}{|c|c|c|c|c|}
\hline Item & Response & $\begin{array}{c}\mathrm{N}=713 \\
\text { Percentage }(\%)\end{array}$ & $\begin{array}{c}\text { Male } \\
\mathrm{N}=512 \\
\text { Percentage }(\%)\end{array}$ & $\begin{array}{c}\text { Female } \\
\mathrm{N}=201 \\
\text { Percentage }(\%)\end{array}$ \\
\hline \multirow{5}{*}{$\begin{array}{l}\text { Commonest type of cancer related } \\
\text { deaths in Jordan }\end{array}$} & Breast & 52.9 & 21.3 & 31.6 \\
\hline & Ovarian & 2.7 & 1.4 & 1.3 \\
\hline & Colorectal & 22.3 & 17.5 & 4.8 \\
\hline & Prostate & 26.8 & 22.4 & 4.4 \\
\hline & Lung & 40.5 & 33.9 & 6.6 \\
\hline \multirow{4}{*}{$\begin{array}{l}\text { Commonest type of cancer related } \\
\text { deaths in Jordan Lifetime } \\
\text { risk of CRC }\end{array}$} & Colorectal & 22.3 & 17.5 & 4.8 \\
\hline & Other types & 77.7 & 82.5 & 95.2 \\
\hline & 1 in 15 & 26.6 & 19.9 & 6.7 \\
\hline & Under or over estimated & 73.3 & 51.9 & 21.5 \\
\hline \multirow{3}{*}{$\begin{array}{l}\text { Number of relatives with colorectal } \\
\text { cancer }\end{array}$} & None & 0.3 & 3.9 & 0 \\
\hline & $\leq 2$ Relative & 5.9 & 47.1 & 35.3 \\
\hline & $\geq 3$ Relative & 1 & 7.8 & 5.9 \\
\hline \multirow[t]{4}{*}{ Lifetime risk of CRC } & 1 in 5 & 5 & 3.8 & 1.3 \\
\hline & 1 in 15 & 26.6 & 19.9 & 6.7 \\
\hline & 1 in 30 & 41.5 & 31.4 & 10.1 \\
\hline & 1 in 60 & 26.8 & 16.7 & 10.1 \\
\hline \multirow[t]{6}{*}{ Perceived risk factors for CRC } & Age & 14.2 & 10.4 & 3.8 \\
\hline & Smoking & 71.7 & 57.1 & 14.6 \\
\hline & Alcohol & 48.1 & 37.7 & 10.4 \\
\hline & Stress & 20.3 & 15.6 & 4.8 \\
\hline & Family history & 39.7 & 24 & 15.7 \\
\hline & Overweight or obesity & 14.4 & 10.4 & 4.1 \\
\hline \multirow{6}{*}{$\begin{array}{l}\text { Common symptoms } \\
\text { of CRC }\end{array}$} & Changes in bowel habits & 23.3 & 15.4 & 7.9 \\
\hline & Rectal Bleeding & 42.2 & 33 & 9.3 \\
\hline & Flautance & 48.8 & 34.8 & 14 \\
\hline & Bloating & 16 & 9.7 & 6.3 \\
\hline & Lack of Exercise & 13 & 8.1 & 4.9 \\
\hline & Digestive system diseases & 35.8 & 27.3 & 8.4 \\
\hline
\end{tabular}

Table 3. Participants Willingness and Preferences to Undergo CRC Screening

\begin{tabular}{|c|c|c|c|c|c|}
\hline Item & Response & $\begin{array}{c}\mathrm{N}=713 \\
\text { ercentage }(\%)\end{array}$ & $\begin{array}{c}\text { Male } \\
\mathrm{N}=512 \\
\text { Percentage }(\%)\end{array}$ & $\begin{array}{c}\text { Female } \\
\mathrm{N}=201 \\
\text { Percentage }(\%)\end{array}$ & $\begin{array}{c}\text { Chi square and } \\
\text { p-value }\end{array}$ \\
\hline Self-rated health status & $\begin{array}{l}\text { Very good or } \\
\text { excellent } \\
\text { Good } \\
\text { Poor or fair }\end{array}$ & $\begin{array}{r}35.5 \\
45.3 \\
19.2 \\
0.3\end{array}$ & $\begin{array}{r}17.4 \\
21.5 \\
3.8 \\
6.7\end{array}$ & $\begin{array}{c}15.9 \\
28.9 \\
11.4 \\
0\end{array}$ & $\begin{aligned} \chi^{2} & =5.74 \\
p & =0.219 \\
\chi^{2} & =3.22\end{aligned}$ \\
\hline Number of relatives with colorectal cancer & $\begin{array}{l}\text { None } \\
\leq 2 \text { Relative } \\
\geq 3 \text { Relative }\end{array}$ & $\begin{array}{l}5.9 \\
1\end{array}$ & $\begin{array}{c}63.3 \\
0\end{array}$ & $\begin{array}{l}52.4 \\
14.3\end{array}$ & $\mathrm{p}=0.199$ \\
\hline Willing to undergo CRC screening & $\begin{array}{l}\text { Yes } \\
\text { No }\end{array}$ & $\begin{array}{l}49.5 \\
50.5\end{array}$ & $\begin{array}{l}33.7 \\
38.1\end{array}$ & $\begin{array}{l}15.8 \\
12.3\end{array}$ & $\begin{aligned} \chi^{2} & =5.04 \\
p & =0.025\end{aligned}$ \\
\hline Believes CRC screening is costly & $\begin{array}{l}\text { Yes } \\
\text { No }\end{array}$ & $\begin{array}{l}71.5 \\
28.5\end{array}$ & $\begin{array}{l}51 \\
20.7\end{array}$ & $\begin{array}{r}20.6 \\
7.7\end{array}$ & $\begin{array}{r}\chi^{2}=163 \\
p=0.687\end{array}$ \\
\hline Preferred CRC Screening Test & $\begin{array}{l}\text { Colonoscopy } \\
\text { Sigmoidoscopy } \\
\text { FOBT }\end{array}$ & $\begin{array}{l}60.4 \\
24.7 \\
14.8\end{array}$ & $\begin{array}{l}42.3 \\
17 \\
10.4\end{array}$ & $\begin{array}{r}18.1 \\
7.7 \\
4.4\end{array}$ & $\begin{aligned} \chi^{2} & =0.048 \\
p & =0.98\end{aligned}$ \\
\hline $\begin{array}{l}\text { Willing to pay for CRC screening if } \\
\text { not covered by insurance } \\
\text { Willing to pay } 500 \text { Jordanian Dinars } \\
\text { (equivalent to } 706 \text { US } \$ \text { ) for Colonoscopy } \\
\text { if requested by physician }\end{array}$ & $\begin{array}{l}\text { Yes } \\
\text { No } \\
\text { Will refuse } \\
\text { Wait for free service } \\
\text { Will pay }\end{array}$ & $\begin{array}{c}85.1 \\
14.4 \\
9 \\
9 \\
\quad 25.5\end{array}$ & $\begin{array}{c}53.6 \\
6.9 \\
5 \\
20.3\end{array}$ & $\begin{array}{c}34.3 \\
5.2 \\
4 \\
5.2 \\
19.2\end{array}$ & $\begin{array}{c}\chi^{2}=7.27 \\
p=.122 \\
\chi^{2}=14.03 \\
p=0.001\end{array}$ \\
\hline
\end{tabular}

and to pay for colonoscopy if requested by physician $(\mathrm{p}=0.001)$.

Factors associated with preference for CRC screening colonoscopy

Out of the 713 participants included in the study $60.4 \%$ stated that they prefer to undergo CRC screening by colonoscopy and $65.5 \%$ were will to pay for the screening colonoscopy if recommended by a physician. As indicated by the results summarized in Table 4 preference for CRC screening using colonoscopy was significantly associated with a belief that CRC screening is costly $(\mathrm{p}=0.000)$ and 
Table 4. Factors Associated with CRC Screening Colonoscopy Preference and Readiness to Pay for Colonoscopy

\begin{tabular}{|c|c|c|c|c|c|}
\hline Item & Response & $\begin{array}{l}\mathrm{N}=713 \\
\text { ercentage }(\%)\end{array}$ & $\begin{array}{c}\text { Prefer } \\
\text { Colonoscopy } \\
\mathrm{N}=203 \\
\text { Percentage }(\%)\end{array}$ & $\begin{array}{c}\text { Prefer Other } \\
\text { tests } \\
\mathrm{N}=139 \\
\text { Percentage }(\%)\end{array}$ & $\begin{array}{l}\text { Chi-square } \\
\text { and p-value }\end{array}$ \\
\hline Willing to undergo CRC screening & $\begin{array}{l}\text { Yes } \\
\text { No }\end{array}$ & $\begin{array}{r}94 \\
6\end{array}$ & $\begin{array}{r}55.8 \\
4.7\end{array}$ & $\begin{array}{l}38.2 \\
14\end{array}$ & $\begin{array}{c}\chi 2=14.60 \\
p=0.100\end{array}$ \\
\hline Believes CRC screening is costly & $\begin{array}{l}\text { Yes } \\
\text { No }\end{array}$ & $\begin{array}{l}61 \\
39\end{array}$ & $\begin{array}{l}34.6 \\
25.8\end{array}$ & $\begin{array}{l}26.4 \\
13.2\end{array}$ & $\begin{array}{r}\chi 2=18.29 \\
\mathrm{p}=0.000\end{array}$ \\
\hline $\begin{array}{l}\text { Willing to pay for CRC screening if } \\
\text { not covered by insurance } \\
\text { Willing to pay } 500 \text { Jordanian Dinars } \\
\text { (equivalent to } 706 \text { US\$) for Colonoscopy } \\
\text { if requested by the physician }\end{array}$ & $\begin{array}{l}\text { Yes } \\
\text { No } \\
\text { Will refuse } \\
\text { Wait for free service } \\
\text { Will pay }\end{array}$ & $\begin{array}{r}85.1 \\
14.4 \\
6.4 \\
18.9 \\
74.7\end{array}$ & $\begin{array}{r}53.6 \\
6.9 \\
2.5 \\
10.6 \\
48.1\end{array}$ & $\begin{array}{r}34.3 \\
5.2 \\
3.8 \\
8.3 \\
26.7\end{array}$ & $\begin{array}{c}\chi 2=7.27 \\
p=0.122 \\
\chi 2=15.36 \\
p=0.004\end{array}$ \\
\hline Item & Response & $\begin{array}{l}\mathrm{N}=698 \\
\text { rrcentage }(\%)\end{array}$ & $\begin{array}{c}\text { Will pay } \\
\mathrm{N}=349 \\
\text { Percentage }(\%)\end{array}$ & $\begin{array}{c}\text { Will not pay } \\
\mathrm{N}=349 \\
\text { Percentage }(\%)\end{array}$ & $\begin{array}{l}\text { Chi-square } \\
\text { and p-value }\end{array}$ \\
\hline Willing to undergo CRC screening & $\begin{array}{l}\text { Yes } \\
\text { No }\end{array}$ & $\begin{array}{l}50 \\
50\end{array}$ & $\begin{array}{l}37.1 \\
28.4\end{array}$ & $\begin{array}{l}12.6 \\
21.6\end{array}$ & $\begin{aligned} \chi 2 & =23.76 \\
p & =0.000\end{aligned}$ \\
\hline Believes CRC screening is costly & $\begin{array}{l}\text { Yes } \\
\text { No }\end{array}$ & $\begin{array}{l}71.1 \\
28.9\end{array}$ & $\begin{array}{l}45 \\
20.5\end{array}$ & $\begin{array}{r}26.1 \\
8.4\end{array}$ & $\begin{aligned} \chi 2 & =3.81 \\
\mathrm{p} & =0.014\end{aligned}$ \\
\hline $\begin{array}{l}\text { Willing to pay for CRC screening if not } \\
\text { covered by insurance }\end{array}$ & $\begin{array}{l}\text { Yes } \\
\text { No }\end{array}$ & $\begin{array}{l}87 \\
13\end{array}$ & $\begin{array}{c}62.5 \\
3\end{array}$ & $\begin{array}{l}24.5 \\
10\end{array}$ & $\begin{array}{r}\chi 2=145.98 \\
p=0.000\end{array}$ \\
\hline
\end{tabular}

willingness to pay colonoscopy if recommended by the physician $(\mathrm{p}=0.004)$.

\section{Discussion}

Our findings in this study add to the growing body of literature assessing CRC awareness, knowledge and patient preferences regarding CRC screening. To our knowledge, there is no formal study has reported about Jordanian patient's CRC awareness and screening tests preferences using a national sample. The finding of this study showing that majority of participants are not aware that CRC is major cause of mortality in Jordan (68\%), underestimated their personal risk for CRC (68.3\%), but were willing to- undergone CRC screening (94\%), pay for CRC screening if not covered by insurance $(85.1 \%$ ) and to pay screening colonoscopy if requested by the physician $(74.7 \%)$. These findings not only highlight the deficiencies in CRC awareness of Jordanian patients, but also the available good foundation and opportunities which can be used to enhance CRC and improve access to CRC screening and prevention.

The finding of this study suggests that there is need for more patient education to increase patient awareness as the country makes efforts to introduce CRC screening initiatives within the Jordanian heath care system. The initiative are mostly to be successful when at risk individuals are more aware of the disease, their personal risk, the benefits of screening for screening and available screening tests. The levels of willingness to undergone screening and preferences for specific CRC screening tests show that the participants were ready to embrace the concept of CRC screening. In this study only $22.3 \%$ of participants correctly ranked CRC as the commonest cause of cancer related deaths in Jordan and the largest number reported as breast cancer to be the commonest cause of cancer mortality in the country. The perception of breast cancer as major cause of cancer mortality by most of the participants may be attributed to the high publicity created by the Jordan Breast Cancer Program.

The findings of this study showing lack of awareness of lifetime personal risk of CRC (only $26.8 \%$ correctly judged their lifetime risk of CRC) are similar to what has been reported in other studies. Harewood and colleagues (2002) that individuals attending out-patient services who have never undergo CRC screening tend to underestimate their risk of the disease $(71 \%)$ compared to those who have been previously screened (48\%). In this study although more than one third of participants were aware of positive family history as a risk factor for CRC, very few $(14.2 \%)$ perceived there increasing risk due to genetic predisposition. Additionally, very few participants were aware that changes in bowel habits $(23.3 \%)$ and rectal bleeding (42.2\%) are common symptoms for CRC. In other studies it has been reported that even outpatients with CRC tend to have limited awareness (only $26.6 \%$ of outpatients could name a symptom of colon cancer) the manifestation of CRC (Manning, Wardon \& Barry 2006). Therefore the findings of this study about awareness imply that in order to enhance CRC screening in Jordan, there is a need first to increase public knowledge about prevalence, symptoms, and risk factors of CRC. An intervention to increase CRC knowledge and awareness at the population level such as media publicity is highly needed.

In this study many of the participants indicated that they were willing to undergo CRC screening tests (49.5\%) and preferred screening by colonoscopy $(60.4 \%)$. These findings suggest a high propensity for CRC screening in Jordanian public and the need for increased access to specific CRC screening tests, especially screening colonoscopy. Strategies to increase access and screening test options may lead to by-in by the patients, increase 
compliance and uptake of CRC screening service. Previous studies have also found variation in patients' preferences for CRC screening tests (Pignone et al., 1998; Ling et al., 2001; Hawley et al., 2008), but it is important to emphasize that the best test for the patient is the one she or he is most likely to adhere to or study complete.

Although the participants for this were recruited from public outpatient gastroenterology clinics, the majority $(60.4 \%)$ were willing to pay for prompt colonoscopy. Literature shows that the cost of CRC screening is frequently reported a major barrier to receipt of screening and implementation of CRC screening programs. This barrier can be augmented by the lack of patient's willingness to bear some of the financial burden associated with CRC screening tests, especially screening colonoscopy. Therefore the findings of this study showing that $66 \%$ were willing to pay to get a prompt CRC screening colonoscopy if recommended by their physician, is a significant opportunity that health care authorities need to take advantage when planning initiative to enhance CRC screening and of cancer prevention. Taking such patients attitude into account can enhance the success of population based programs.

The findings of this study should be interpreted in view of the limitations such as the self-report method of data collection, lack of information about participant prior receipt of CRC screening, and the effect of response bias since the sample was obtained using convenience method and from gastroenterology clinics. Therefore it is possible that the patients attending these clinics were more informed about CRC and motivated to undergo screening than the average population. Despite the limitations, this is the first study to document the CRC screening tests preferences of Jordanians in any health care setting and provides important insights into the knowledge deficits among patients regarding CRC.

In conclusion, the findings of this study present the health authorities responsible for planning for health services and clinicians responsible for providing CRC screening services with insights of how to strategically enhance CRC screening and prevention in Jordan. The study highlights a significant lack of awareness by at risk patients of the contribution of CRC to cancer mortality in Jordan, personal life time risk for CRC, CRC risk factors and warning symptoms. Therefore interventions to increase the population's awareness and knowledge about CRC are needed and should be part of any population based program to enhance screening and prevention. The participants CRC screening test preferences, and the number willing to undergo screening and to bear the financial cost of CRC screening demands, show a very high propensity for screening. The high propensity CRC screening indicates a need for increased access to various types of CRC screening tests and to create options for costshared services in order to get prompt screening among those who can afford.

\section{Acknowledgements}

We want to thank all patients who participated in the study for their cooperation. We also want to acknowledge the efforts of Roya Aldebei for data analysis. The study was funded by Deanship of Research/ Philadelphia University.

\section{References}

Agency for Health Care policy and Research (2005). http://www. ahrq.gov/clinic/colorsum.htm.

American Cancer Society (2007). Cancer facts and figures. www. cancer.org. Accessed June, 2011.

American Cancer Society (2006). Cancer facts and figures. Atlanta: American cancer society.

Dolan NC, Ferreira MR, Davis TC, et al (2004). Colorectal cancer screening knowledge, attitudes, and beliefs among persons of lower socioeconomic status: does literacy make a difference? J Clin Oncol, 22, 2617-22.

Hannon PA, Martin DP, Harris JR, Bowen D (2008). Colorectal cancer screening practices of primary care physicians in Washington State. Cancer Control, 15, 174-81.

Hardcastle JD, Chamberlain JO, Robinson MHE, et al (1996). Randomized clinical trial of fecal occult blood screening for colorectal cancer. Lancet, 348, 1472-7.

Harewood GC, Melton LJ, Wiersema MJ (2002). A prospective, controlled assessment of factors influencing acceptance of screening colonoscopy. Am J Gastroenterol, 97, 3186-94.

Hawley ST, Volk RJ, Krishnamurthy P, Jibaja-Weiss ML, Vernon SW, Kneuper S (2008). Preferences for colorectal cancer screening among racially/ ethnically diverse primary care patients. Medical Care, 46, 5-9.

Huxley RR, Ansary-Moghaddam AA, Clifton P, et al (2009). The impact of dietary and life style risks of colorectal cancer: A quantitative overview of the epidemiology evidence. Intern J Cancer, 125, 171-80.

Klabunde CN, FSchenck A, Davis W (2006). Barriers to colorectal cancer among medicare consumers. Am J Prev Med, 30, 313-9.

Ling BS, Moskowitz MA, Wachs D, Pearson B, Schroy PC (2001) Attitudes toward colorectal cancer screening tests. $J$ General Int Med, 16, 822-30.

Lieberman DA (1995). Cost-effectiveness model for colon cancer screening. Gastroenterology, 109, 1781-90.

Manning A T, Waldron R, Barry K (2006). Poor awareness of colorectal cancer symptoms; a preventable cause of emergency and late stage presentation. Irish J Med Sci, 175, 55-7.

Mandel JS, Bond JH, Church TR, et al (1993). Reducing mortality from colorectal cancer by screening for fecal occult blood. minnesota colon cancer control study. New England $J$ Med, 328, 1365-71.

Mandelblatt J, Andrews H, Kao R, et al (1996). The late stage diagnosis of colorectal cancer: Demographic and socioeconomic factors. Am J Public Health, 86, 1794-7.

Meissner Breen N, Klabunde C, Vernon S (2006). Patterns of colorectal cancer screening uptake among men and women in the United States. Cancer Epidemiol Bio Prev, 15, 389-94.

Musaiger AO (2004). Overweight and obesity in the Eastern Mediterranean Region: Can we control it? Eastern Mediterranean Health J, 10, 789-93.

National Cancer Registry (NCR) (2010). Cancer incidence in Jordan report of 2009. Non-Communicable Diseases Control Section, Amman, Jordan.

Omran S, Ismail AA (2010). Knowledge and beliefs of Jordanians toward colorectal cancer screening. Cancer Nursing, 33, 141-8.

Pignone MP, Bucholtz D, Harris R (1998). Patient interest and preferences for colon cancer Screening. J General Intern Med, 13, 96. 
Schoen RE, Pinsky PF, Weissfeld JL, et al (2012). PLCO Project Team. Colorectal-cancer incidence and mortality with screening flexible sigmoidoscopy. New Engl J Med, 366, 2345-57.

Shapiro JA, Seeff LC, Thompson TD, et al (2008). Colorectal cancer test use from the 2005 National health interview survey. Cancer Epidemiol Biomarkers Prev, 17, 1623-30.

Seef LC, Nadel MR, Klabunde CN, et al (2004). Patterns and predictors of colorectal cancer test use in the adult US population. Cancer, 100, 2093-103.

Swan J, Breen N, Coates R, Rimer B, Lee N (2003). Progress in cancer screening practices in the United States: results from the 2000 national interview survey. Cancer, 97, 1528-40.

Tarawneh M, Nimri O (2008). Cancer incidence in Jordan. ministry of health: non communicable diseases directorate. Amman, Jordan Cancer Registry.

Umar A, Greenward P (2009). Alarming colorectal cancer incidence trends: a case for early detection. Cancer Epidemiol Biomarkers Prev, 18, 1672-3.

U.S. Preventive Service Task Force (2008). Screening for colorectal cancer: recommendations and rationale. Ann Int Med, 137, 129-31.

US Department of Health and Human Services, Health Resources and Services Administration (2010). National Data. bphc. hrsa.gov/uds/view.aspx?year52010. Accessed December $30,2014$.

WHO (2011). Cancer. Accessed on June, 2014. http://www.who. int/mediacentre/factsheets/fs279/en/index.html

World Health Organization (2015). Cancer Country Profiles. Access from http://www.who.int/cancer/country-profiles/ jor_en.pdf?ua=1 on 2 February, 2015.

Winawer S, Fletcher R, Rex D, et al. (2003).Colorectal cancer screening and surveillance: Clinical guidelines and rationaleupdate based on new evidence. Gastroenterology, 124, 544-60. 